\title{
PTEN Coding Region Mutation Present
}

National Cancer Institute

\section{Source}

National Cancer Institute. PTEN Coding Region Mutation Present. NCI Thesaurus. Code C146986.

A genetic finding indicating that a sample has one or more exon mutations in the PTEN gene. 